\title{
Experimental Demonstration of a Cognitive Quality of Transmission Estimator for Optical Communication Systems
}

Caballero Jambrina, Antonio; Aguado, Juan Carlos; Borkowski, Robert; Saldaña Cercos, Silvia; Jiménez, Tamara; de Miguel, Ignacio; Arlunno, Valeria; Durán, Ramón J.; Zibar, Darko; Jensen, Jesper Bevensee Total number of authors:

13

Published in:

ECOC Technical Digest

Link to article, DOI:

10.1364/ECEOC.2012.We.2.D.3

Publication date:

2012

Document Version

Publisher's PDF, also known as Version of record

Link back to DTU Orbit

Citation (APA):

Caballero Jambrina, A., Aguado, J. C., Borkowski, R., Saldaña Cercos, S., Jiménez, T., de Miguel, I., Arlunno, V., Durán, R. J., Zibar, D., Jensen, J. B., Lorenzo, R. M., Abril, E. J., \& Tafur Monroy, I. (2012). Experimental Demonstration of a Cognitive Quality of Transmission Estimator for Optical Communication Systems. In ECOC Technical Digest (pp. We.2.D.3). Optical Society of America. https://doi.org/10.1364/ECEOC.2012.We.2.D.3

\section{General rights}

Copyright and moral rights for the publications made accessible in the public portal are retained by the authors and/or other copyright owners and it is a condition of accessing publications that users recognise and abide by the legal requirements associated with these rights.

- Users may download and print one copy of any publication from the public portal for the purpose of private study or research.

- You may not further distribute the material or use it for any profit-making activity or commercial gain

- You may freely distribute the URL identifying the publication in the public portal 


\title{
Experimental Demonstration of a Cognitive Quality of Transmission Estimator for Optical Communication Systems
}

\author{
Antonio Caballero ${ }^{(1)}$, Juan Carlos Aguado ${ }^{(2)}$, Robert Borkowski ${ }^{(1)}$, Silvia Saldaña ${ }^{(1)}$, Tamara Jiménez ${ }^{(2)}$, \\ Ignacio de Miguel ${ }^{(2)}$, Valeria Arlunno ${ }^{(1)}$, Ramón J. Durán ${ }^{(2)}$, Darko Zibar ${ }^{(1)}$, Jesper B. Jensen ${ }^{(1)}$, Rubén \\ M. Lorenzo ${ }^{(2)}$, Evaristo J. Abril ${ }^{(2)}$, Idelfonso Tafur Monroy ${ }^{(1)}$ \\ (1) DTU Fotonik, Tech. Univ. of Denmark, DK-2800 Kgs. Lyngby, Denmark, acaj@fotonik.dtu.dk \\ (2) University of Valladolid, Valladolid, Spain, jaguado@tel.uva.es
}

\begin{abstract}
We report on the experimental performance of a case-based reasoning technique to predict whether optical channels fulfill quality of transmission requirements, thus supporting impairment-aware networking. Validation is performed in a WDM $80 \mathrm{~Gb} / \mathrm{s}$ PDM-QPSK testbed.
\end{abstract}

\section{Introduction}

Next generation optical networks will be of a highly heterogeneous nature, as they will support mixed bit-rates, mixed modulation formats and even a flexible grid for spectrum allocation. That arising scenario brings new challenges in terms of transmission robustness, optical monitoring and mechanisms for control and management. One of those challenges is the need for new estimation techniques to predict the quality of transmission (QoT) of optical connections before being established in the network, thus supporting impairment-aware networking. The use of cognition, and specifically the use of previous experiences, can help overcome the latter issue.

We have recently proposed a novel cognitive QoT estimator ${ }^{2}$ which is able to predict whether a new lightpath to be established in an optical network will comply with QoT requirements (and if it will not have a significant impact on previously established ones). The estimator relies on Case-Based Reasoning (CBR) techniques $^{3}$. CBR is an artificial intelligence mechanism which solves a new problem by looking for the most similar problems (or cases) faced in the past, and by reusing that knowledge, either directly or after some adaptation, to provide a solution. In this way, by exploiting previous experiences, which are stored on a knowledge base (KB), the QoT estimator is able to provide fast and correct decisions on whether a lightpath fulfills QoT requirements or not, before being established, without having to rely on complex methods. Using that technique, we have demonstrated, by means of simulation, that lightpaths in a $10 \mathrm{~Gb} / \mathrm{s}$ OOK 14-node wavelength-routed optical network are correctly classified into high or low QoT categories in more than $99 \%$ of cases, with a very low computing time ${ }^{2}$.

In this paper, we push forward that work by experimentally demonstrating that cognition can be successfully employed to predict the QoT of optical channels. At this stage, rather than implementing a whole network, a wavelength division multiplexed (WDM), homogeneous $80 \mathrm{~Gb} / \mathrm{s}$ polarization division multiplexed (PDM) quadrature and phase-shift keying (QPSK) point-to-point optical transmission system has been built, with a number of adjustable parameters such as the optical launch power, the fiber link length and the number of copropagating channels, in order to support different lightpath and system configurations.

\section{Experimental setup}

Fig. 1 shows the WDM experimental setup for quality of transmission experiment of PDMQPSK at $80 \mathrm{Gbit} / \mathrm{s}$ through $480 \mathrm{~km}$ of dispersion compensated fiber link. At the transmitter side, 5 laser sources spaced $50 \mathrm{GHz}$ apart are combined using a $50 \mathrm{GHz}$ arrayed waveguide grating (AWG), 4 of them distributed feedback lasers ( $3 \mathrm{MHz}$ linewidth) and an external cavity laser (ECL) with $100 \mathrm{kHz}$ linewidth placed in the central channel. $20 \mathrm{Gbit} / \mathrm{s}$ electrical signals are generated using a $5 \mathrm{Gbit} / \mathrm{s}$ pulse pattern generator (PPG) with PRBS $2^{15}-1$ and a $4: 1$ electrical interleaver (IL). The electrical signals are used to drive a double-nested MachZehnder modulator fed by the 5 optical sources. Polarization division multiplexing is emulated by multiplexing the signal with its delayed copy in the orthogonal polarization. Afterwards the odd and even channels are decorrelated using a $50 \mathrm{GHz}$ optical interleaver and a $3 \mathrm{~dB}$ optical coupler, by introducing an optical delay of 23 ps between odd and even channels. After that, an erbium-doped fiber amplifier (EDFA) is used to amplify the signal to the desired launch power.

Fiber transmission is realized over a maximum of 6 fiber spans of $80 \mathrm{~km}$ standard single mode fiber (SSMF) and matched dispersion compensating fiber (DCF), for a total maximum distance of $480 \mathrm{~km}$. After each fiber 


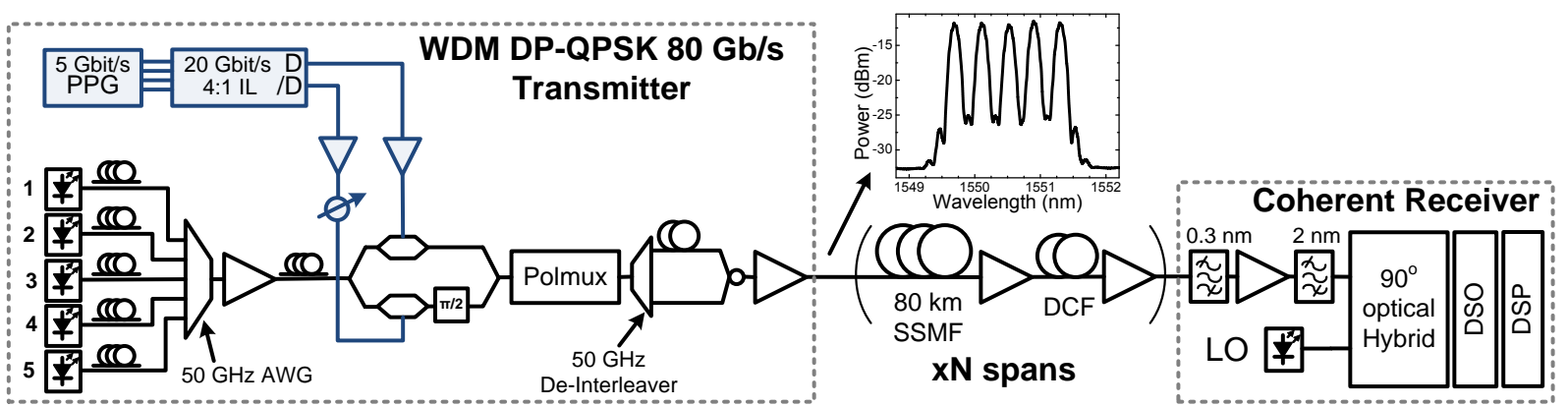

Fig. 1: Experimental setup. PPG: pulse pattern generator, Polmux: polarization multiplexed stage.

span, the optical signal is amplified in a doublestage EDFA with the DCF placed between the two stages. The gain of the amplification stage is adjusted to compensate for each span and DCF losses. In some scenarios $4 \mathrm{~dB}$ extra span losses are added at the end of each fiber span to achieve $22 \mathrm{~dB}$ of losses per span.

At the receiver side, a preamplified coherent detection scheme is used. It consists of a $0.3 \mathrm{~nm}$ optical filter for channel selection, pre-amp EDFA, a $2 \mathrm{~nm}$ optical filter to remove amplified spontaneous emission excess noise and a polarization-diversity coherent receiver with integrated balanced photodiodes. An ECL with $100 \mathrm{kHz}$ linewidth is employed as local oscillator (LO). A digital sampling oscilloscope (DSO) with $40 \mathrm{GS} / \mathrm{s}$ of sampling rate and $13 \mathrm{GHz}$ bandwidth is used to digitize the photodiodes outputs. The acquired data is processed offline with a digital signal processing-based (DSP-based) receiver that includes digital filter, constant modulus algorithm (CMA), carrier phase recovery and root mean squared (RMS) error vector magnitude (EVM) calculation.

In order to emulate different lightpaths and system configurations in an optical network, the experimental setup allows for the modification of some parameters: the number of simultaneously active channels in the link (from 2 to 5), the power per channel (from -4 to $4 \mathrm{dBm}$ in steps of $2 \mathrm{~dB}$ ), the number of spans (3 or 6 , thus testing lightpath lengths of 240 and $480 \mathrm{~km}$ ), and the losses per span (18 or $22 \mathrm{~dB}$ ). In this way, different scenarios have been configured, and the RMS EVM of each of the active channels in each configuration has been experimentally measured, which is an indicator of the QoT of each channel.

\section{A cognitive QoT estimator based on CBR}

We have developed a cognitive QoT estimator, based on CBR, for the testbed described above. The KB is composed of a number of cases, each consisting of a description of the lightpath and its associated (measured) EVM. Those cases have been experimentally obtained by setting the testbed with different parameters, as previously explained.

The description of the lightpath contains the channel wavelength, the launch power, the losses per span and the number of spans (i.e., the lightpath length), the set of active wavelength channels (i.e., the active lightpaths) in the link, the total input power to the link, and the total power carried by the adjacent channels of the lightpath considered, as well as that carried by those located 2, 3 and 4 channel slots apart from it. The measured EVM in the experimental tesbed for each lightpath and each configuration is also stored in the KB.

Let us assume that the QoT of a new lightpath must be assessed. The cognitive QoT estimator works as follows. First of all, it retrieves the most similar lightpath from the KB to the one to be analyzed. In order to assess the similarity when comparing the new lightpath with those contained in the $K B$, the weighted Euclidean distance is calculated ${ }^{4}$, where the set of weights associated to the different parameters that describe a lightpath has been previously determined based on a linear regression. The EVM of the new lightpath is assumed to be the same one than that of the retrieved case, and that value is used to decide whether the lightpath fulfills the QoT requirements or not. For that purpose, the EVM is compared with a threshold. If it is lower than the threshold, the lightpath is classified into the high QoT category, otherwise it is classified into the low QoT category.

\section{Performance results of the cognitive QoT estimator}

In order to evaluate the performance of the cognitive QoT estimator, we have set the testbed with different configurations and measured the EVM of the different channels. In that way, a total of 153 cases have been experimentally compiled, with EVM values ranging from $14.4 \%$ to $24.9 \%$. 
Then, we have used the 10-fold cross validation technique. This is a standard technique to analyze the success rate of machine learning algorithms ${ }^{5}$. The available data (the set of 153 cases) is randomly divided into 10 parts. Nine parts are used to compose the $\mathrm{KB}$, and the remaining part is used to test the cognitive estimator (i.e., the cases of that part are classified by the estimator and the ratio of successful classifications is calculated). The procedure is repeated 10 times (each time using a different portion for the test set, and the remaining parts to build the $\mathrm{KB}$ ), and the results are averaged.

Fig. 2 represents the percentage of successful classifications provided by the cognitive QoT estimator when setting different values of the EVM as the threshold to differentiate between high and low QoT categories. The results are compared with a majority class classification. Let $S_{h}$ be the success ratio obtained if all the lightpaths are classified into the high QoT class, and $S$, be the success ratio obtained if all the lightpaths are classified into the low QoT category. Then the majority class classification provides $\max \left(S_{h}, S_{l}\right)$. In other words, the results are compared with the percentage of cases belonging to the most likely class. As shown in Fig. 2, the cognitive QoT estimator improves the ratio of successful classifications between 5.8 (for an EVM threshold of 23\%) and 29.0 (for an EVM threshold of $18.5 \%$ ) percentage points when compared with the majority class classification. Moreover, the successful classifications are higher than $79 \%$ in all cases, and even higher than $90 \%$ except when the EVM threshold is set between 18 and $20.5 \%$. The success ratio is lower than that obtained previously ${ }^{2}$, but it should be noted that the scenario is different

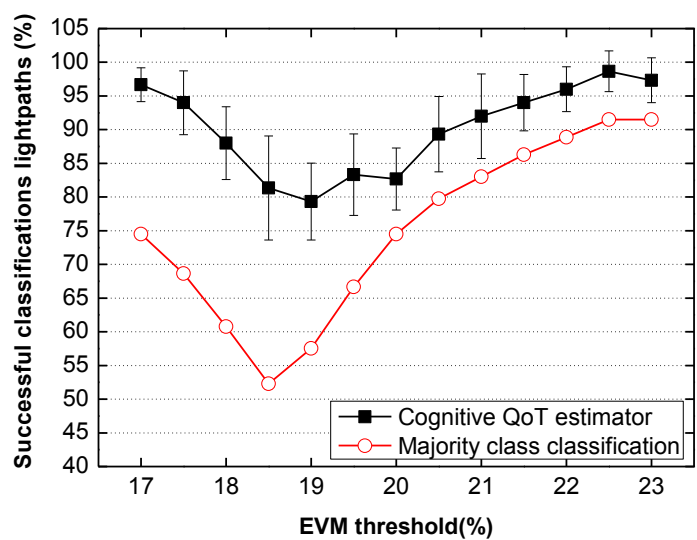

Fig. 2: Percentage of successful classifications of lightpaths into high/low QoT categories.

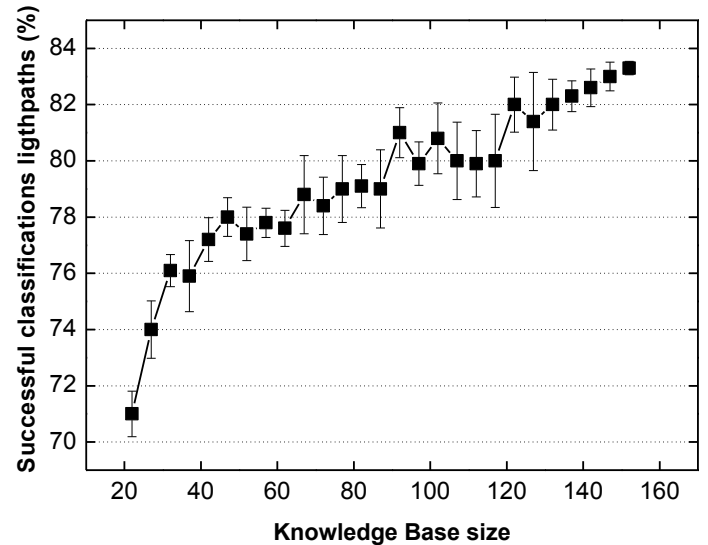

Fig. 3: Impact of the size of the knowledge base.

and, more importantly, that in this case the size of the KB is very small (nine-tenths of 153, i.e., 135 cases).

To further analyze the impact of the size of the $K B$, we have studied the performance of the cognitive QoT estimator for different KB sizes, running from 22 to 152 cases, when considering an EVM threshold of $19.5 \%$. In this occasion, a leave- $n$-out cross validation technique ${ }^{5}$ has been used, setting $n$ to different values in order to get the desired size of the KB. As shown in Fig. 3 the success ratio of the classifications increases with the size of the KB.

\section{Conclusions}

We have experimentally demonstrated the use of a CBR technique to assess whether lightpaths comply with QoT requirements. Even with a very small $\mathrm{KB}$, it achieves between $79 \%$ and $98.7 \%$ successful classifications, showing its potential for application in cognitive optical networking.

\section{Acknowledgements}

This work was partly supported by the EU FP7 project CHRON under grant agreement no. 258644. T. Jiménez would like to thank the Council of Education of the Regional Government of Castilla-León and the European Social Fund for their support.

\section{References}

[1] S. Azodolmolky et al., J. Lightwave Technol. 29, 439 (2011).

[2] T. Jiménez et al., Proc. OFC'12, OW3A.5 (2012).

[3] A. Aamodt et al., Artificial Intelligence Communications 7, 39-59 (1994).

[4] D. W. Aha, Int. J. Man-Machine Studies 36, 267-287 (1992).

[5] I. H. Witten et al., Data Mining: Practical Machine Learning Tools and Techniques, $3^{\text {rd }}$ ed., Morgan Kaufmann (2011). 